\title{
hcp-phased Ni nanoparticles with generic catalytic hydrogenation activities toward different functional groups
}

\author{
Yang $\mathrm{Lv}^{1 \dagger}$, Xin $\mathrm{Mao}^{2 \dagger}$, Wanbing Gong ${ }^{1,3^{*}}$, Dongdong Wang ${ }^{1}$, Chun Chen ${ }^{1}$, Porun Liu ${ }^{4}$, Yue $\operatorname{Lin}^{3}$, \\ Guozhong Wang ${ }^{1}$, Haimin Zhang ${ }^{1}$, Aijun $\mathrm{Du}^{2^{*}}$ and Huijun Zhao ${ }^{1,4^{*}}$
}

\begin{abstract}
Catalytic hydrogenation is a vital industrial means to produce value-added fuels and fine chemicals, however, requiring highly efficient catalysts, especially the nonprecious ones. To date, the majority of high-performance industrial hydrogenation catalysts are made of precious metals-based materials, and any given catalyst could only be used to catalyze one or few specific reactions. Herein, we exemplify a crystal phase engineering approach to empower $\mathrm{Ni}$ nanoparticles (NPs) with superb intrinsic catalytic activities toward a wide spectrum of hydrogenation reactions. A facile pyrolysis approach is used to directly convert a Ni-imidazole MOF precursor into hexagonal close-packed (hcp)-phased Ni NPs on carbon support. The as-synthesized hcp-phased Ni NPs exhibit unprecedented hydrogenation catalytic activities in pure water towards nitro-, aldehyde-, ketone-, alkene- and $\mathbf{N}$ heterocyclic-compounds, outperforming the face-centered cubic (fcc)-Ni counterpart and the reported transition metalsbased catalysts. The density functional theory calculations unveil that the presence of hcp-Ni boosts the intrinsic catalytic hydrogenation activity by coherently enhancing the substrate adsorption strength and lowering the reaction barrier energy of the rate-determining step. We anticipate that the crystal phase engineering design approach unveiled in this work would be adoptable to other types of reactions.
\end{abstract}

Keywords: crystal phase engineering, hcp-phased $\mathrm{Ni}$ nanoparticles, catalytic hydrogenation, DFT calculations, $\mathrm{H}_{2} \mathrm{O}$ solvent

\section{INTRODUCTION}

Catalytic hydrogenation (CH) of nitro-, aldehyde-, ketone- and alkene-functional groups and $\mathrm{N}$-containing heterocyclic compounds is a vital industrial means to produce high value-added fuels and fine chemicals, however, requiring cheap and highly efficient $\mathrm{CH}$ catalysts [1-13]. Enormous efforts have been devoted to exploring different activation approaches capable of boosting the $\mathrm{CH}$ activity of cheap and plentiful transition-metal
(TM) catalysts, including alloying/de-alloying [14-16], defect and strain engineering [17,18], structure and composition manipulations $[19,20]$. A promising strategy that has recently received increasing attention is engineering TM nanoparticles (NPs) with hexagonal close-packed (hcp) crystal phase to enhance the intrinsic $\mathrm{CH}$ performance [21-24]. For instance, Bao and Zhu's group [21,22] reported a non-hydrolytic thermal decomposition approach to controllably synthesize hcp-Ni NPs from $\mathrm{Ni}(\mathrm{COOH})_{2}$ as a $\mathrm{CH}$ catalyst to efficiently hydrogenate nitrophenols to aminophenols. Janiak and co-workers [23] demonstrated a synthetic method based on the microwaveinduced decomposition of $\mathrm{Ni}$-containing salts to synthesize the metastable hcp-Ni NPs. Under $100^{\circ} \mathrm{C}$ and 5 bar $\mathrm{H}_{2}$ pressure, the synthesized hcp-Ni NPs can hydrogenate 1-hexene and benzene with $90 \%$ conversion efficiencies within 1 and $60 \mathrm{~h}$, respectively. Very recently, a reductive pyrolysis of metal-organic framework (MOF) approach was reported by Fan's group [24] to fabricate graphene-encapsulated hcp-Co with outstanding $\mathrm{CH}$ performance towards a wide spectrum of carboxyl-containing compounds. In addition to thermo-catalytic hydrogenation, engineering TM with hcp phases has also been applied to photoand electro-catalysis [25-27]. For example, Yan's group [25] demonstrated a "phase-mediated" strategy, where hcp-Co@NC and face-centered cubic (fcc)-Co@NC have been employed for hydrogen and oxygen evolution reactions (HER/OER). They demonstrated that when fcc-Co@NC was converted to hcpCo@NC, both HER and OER over-potentials could be dramatically decreased, confirming the effectiveness of hcp phase for overall water splitting. These successful exemplifications have been systematically reviewed by Zhang's group [27], which depicted that engineering nanomaterials' crystal phase is an effective approach to endow nanomaterials with promising catalytic properties.

Despite the noticeable progress, the controllable synthesis of hcp-phased TM catalysts remains a challenging task. To date, the reported TM catalysts with hcp crystal phases are almost exclusively synthesized by wet-chemical methods that require

\footnotetext{
${ }^{1}$ Key Laboratory of Materials Physics, Centre for Environmental and Energy Nanomaterials, Anhui Key Laboratory of Nanomaterials and Nanotechnology, Institute of Solid State Physics, Hefei Institutes of Physical Science, Chinese Academy of Sciences, Hefei 230031, China

${ }^{2}$ School of Chemistry, Physics and Mechanical Engineering, Science and Engineering Faculty, Queensland University of Technology, Gardens Point Campus, Brisbane, QLD 4001, Australia

${ }^{3}$ Hefei National Laboratory for Physical Sciences at the Microscale, University of Science and Technology of China, Hefei 230026, China

${ }^{4}$ Centre for Catalysis and Clean Energy, Griffith University, Gold Coast Campus, Queensland 4222, Australia

$\dagger$ These authors contributed equally to this work.

*Corresponding authors (emails: h.zhao@griffith.edu.au (Zhao H); wbgong2021@ustc.edu.cn (Gong W); aijun.du@qut.edu.au (Du A))
} 
the use of organic ligands to stabilize the hcp phase [28]. It is known that the presence of such organic ligands inevitably slows the reactant transport to the catalyst active sites, leading to the decreased catalytic performance and potential contamination of the final products. To this end, MOFs with metal-nodes and carbon containing organic ligands have shown notable advantages for the fabrication of highly dispersed TM NPs with unique crystal structures for important catalytic reactions [29,30]. So far, the successful examples of using MOFs as precursors to directly synthesize hcp-phased TM catalysts are mostly for Co NPs $[24,25,29]$. For instance, $\mathrm{Co}_{3}\left[\mathrm{Co}(\mathrm{CN})_{6}\right]_{2} \mathrm{MOF}$ was used to synthesize hcp-Co NPs via a carbonization process under $\mathrm{N}_{2}$ protective atmosphere at $800^{\circ} \mathrm{C}$; nevertheless, $\mathrm{Ru}$ doping was required to trigger the growth of hcp-phased Co [24]. Zhang and co-workers [29] reported the use of chemical vapor deposition of ethyne to controllably reduce Co-MOF precursor to Co NPs with fcc and hcp phases. They unveiled that the ratio of hcp and fcc phases in the resultant Co NPs can be controlled by precisely controlling the deposition temperatures. Nonetheless, using MOFs as precursors to directly synthesize hop-phased Ni NPs via a one-step process has yet been reported, which is due mainly to the comparatively high stability of fcc-phased Ni over hcp-phased Ni [31].

Herein, we report a facile pyrolysis approach to directly convert a Ni-imidazole $\left(\mathrm{Ni}(\mathrm{im})_{x}\right.$ ) MOF precursor into hcpphased Ni NPs covered by a thin N-doped carbon layer (denoted as hcp/fcc-Ni). Notably, the obtained hcp/fcc-Ni exhibits the unprecedented $\mathrm{CH}$ activities towards a wide spectrum of substrates including nitro-, aldehyde-, ketone-, alkene- and $\mathrm{N}$ heterocyclic-compounds. Density functional theory (DFT) calculations demonstrate that the presence of hcp phase enhances the substrate adsorption strength and lowers the reaction barrier energy of the rate-determining step.

\section{EXPERIMENTAL SECTION}

\section{Chemicals}

Imidazole and nitric acid $\left(\mathrm{HNO}_{3}\right)$ were purchased from Aladdin Reagent Company. Nickel acetate tetrahydrate $\left(\mathrm{Ni}\left(\mathrm{CH}_{3} \mathrm{COO}\right)_{2} \cdot 4 \mathrm{H}_{2} \mathrm{O}\right)$, ethanol and ammonium hydroxide $\left(\mathrm{NH}_{3} \cdot \mathrm{H}_{2} \mathrm{O}\right)$ were purchased from Sinopharm Chemical Reagent Co. Ltd. Unless otherwise stated, all other solvents and chemicals were of commercially available analytical grade and used without further purification. All solutions were prepared using deionized water $(>18.2 \mathrm{M} \Omega)$.

\section{Synthesis of $\mathrm{Ni}(\mathrm{im})_{x}$}

In a typical synthesis, imidazole $(1.17 \mathrm{~g}, 17 \mathrm{mmol})$ was added to $50 \mathrm{~mL}$ of aqueous solution containing $2.83 \mathrm{mmol}$ of $\mathrm{Ni}\left(\mathrm{CH}_{3} \mathrm{COO}\right)_{2} \cdot 4 \mathrm{H}_{2} \mathrm{O}$, and quickly mixed with $5 \mathrm{~mL}$ of $\mathrm{NH}_{3} \cdot \mathrm{H}_{2} \mathrm{O}$. The resultant solution was transferred into a $100-\mathrm{mL}$ vial and stirred for $20 \mathrm{~min}$. The vial was then placed in a Teflon-lined stainless-steel autoclave and heated at $90^{\circ} \mathrm{C}$ for $6 \mathrm{~h}$. The asobtained yellow precipitates were collected by air pump filtration, washed by deionized water and ethanol three times, and dried at $60^{\circ} \mathrm{C}$ for $24 \mathrm{~h}$ in a vacuum oven.

\section{Synthesis of hcp/fcc-Ni and fcc-Ni}

To synthesize hcp/fcc-Ni, $500 \mathrm{mg}$ of the synthesized $\mathrm{Ni}(\mathrm{im})_{x}$ precursor was placed in a ceramic boat and heated to $400^{\circ} \mathrm{C}$ with a heating ramp of $2^{\circ} \mathrm{C} \mathrm{min}^{-1}$ under $10 \mathrm{vol} \% \mathrm{H}_{2} / \mathrm{Ar}$ flow and maintained at this condition for $2 \mathrm{~h}$. After naturally cooling down to the room temperature, the black powder was obtained and labelled as hcp/fcc-Ni. The fcc-Ni was synthesized via the same procedure as that used for hcp/fcc-Ni, except that Ar was used to replace $10 \mathrm{vol} \% \mathrm{H}_{2} /$ Ar during the pyrolysis.

\section{Catalyst characterizations}

Field emission scanning electron microscopy (FESEM) measurements were performed on an FESEM (SU8020) operated at an accelerating voltage of $5.0 \mathrm{kV}$. Powder X-ray diffraction (XRD) patterns were recorded on a Philips X-Pert Pro X-ray diffractometer using $\mathrm{Ni}$-filtered monochromatic $\mathrm{Cu} \mathrm{Ka}$ radiation $\left(\lambda \mathrm{K}_{\alpha 1}=1.5418 \AA\right)$ at $40 \mathrm{kV}$ and $40 \mathrm{~mA}$. Transmission electron microscopy (TEM) tests were carried out using JEOL2010 at $200 \mathrm{kV}$. High-angle annular dark field scanning transmission electron microscopy (HAADF-STEM) images were carried out on Philips TecnaiG2 F20 operated at an acceleration voltage of $200 \mathrm{kV}$ with an EDS Oxford, Link ISIS. AC HAADFSTEM images were recorded by a JEOL JEM-ARM 200F fieldemission transmission electron microscope with a spherical aberration corrector. The specific surface area, pore volume and pore size of the catalysts were calculated using a BET (BrunauerEmmett-Teller) instrument (Autosorb iQ Station 2). X-ray photoelectron spectroscopy (XPS) spectra were performed by an ESCALAB 250 X-ray photoelectron spectrometer (Thermo, USA) equipped with Al $\mathrm{K}_{a 1,2}$ monochromatized radiation at $1486.6 \mathrm{eV}$ X-ray source. The metal contents in different samples were determined by inductively coupled plasma mass spectrometer (ICP 6300, Thermo Fisher Scientific).

\section{Performance evaluations}

All catalytic hydrogenation reactions were carried out in a $25-\mathrm{mL}$ stainless steel autoclave equipped with a mechanical stirrer, a pressure gauge, and automatic temperature control apparatus (Anhui Kemi Machinery Technology Co., Ltd). For a typical run, $0.5 \mathrm{mmol}$ of reaction substrate, $20 \mathrm{mg}$ of catalyst, and $10 \mathrm{~mL}$ of solvent were added into the reactor. The air in the reactor was thoroughly replaced by $1 \mathrm{MPa} \mathrm{N}_{2}$ three times. The reactor was firstly pressurized with $\mathrm{H}_{2}$ to a desired pressure, then heated to a required temperature and maintained the temperature for a pre-determined period (the reaction time). A stirring speed of $700 \mathrm{r} \mathrm{min}^{-1}$ was used for all the experiments. The obtained reaction solution was filtered through a filter membrane $(0.22 \mu \mathrm{m})$ and extracted by ethyl acetate for three times. The reaction products in the extraction solution were identified by gas chromatography mass spectrometry (GC-MS, Thermo Fisher Scientific-TXQ), and then quantitatively analyzed by GC (Shimadzu, GC-2010 Plus) using $n$-octanol as an internal standard. For cycling tests, the used catalyst was collected by an external magnet, washed by ethanol, and dried at $60^{\circ} \mathrm{C}$ for $24 \mathrm{~h}$ in a vacuum oven.

\section{DFT calculations}

Density functional theory as implemented in the Vienna $a b$ initio Simulation Package (VASP) was employed to optimize geometry structures $[32,33]$. The exchange-correlation interactions were described by the generalised gradient approximation (GGA) [34] in the form of the Perdew-Burke-Ernzerhof (PBE) functional [35]. A cut-off energy of $500 \mathrm{eV}$ for plain-wave basis sets was adopted and the convergence threshold was set to $10^{-5} \mathrm{eV}$, and $5 \times 10^{-3} \mathrm{eV} \AA^{-1}$ for energy and force, respectively. 
The weak interaction was described by DFT+D3 method using empirical correction in Grimme's scheme [36]. The vacuum space was set to be more than $20 \AA$, which was enough to avoid the interaction between periodical images. For fcc-Ni and hcpNi models, a four layer of $6 \times 6$ supercell was used with the last two layers fixed. The minimum energy pathway for the oxidation process was determined by using a climbing image nudged elastic band method (CINBE) implemented in the VASP code
$[37,38]$.

\section{RESULTS AND DISCUSSION}

\section{Synthesis and structural characteristics of hcp/fcc-Ni}

Fig. 1a schematically illustrates the typical synthetic procedure for the fabrication of $\mathrm{hcp} / \mathrm{fcc}-\mathrm{Ni}$. In brief, the polycrystallinestructured $\mathrm{Ni}(\mathrm{im})_{x}$ MOF nanofiber precursor having $50-100 \mu \mathrm{m}$
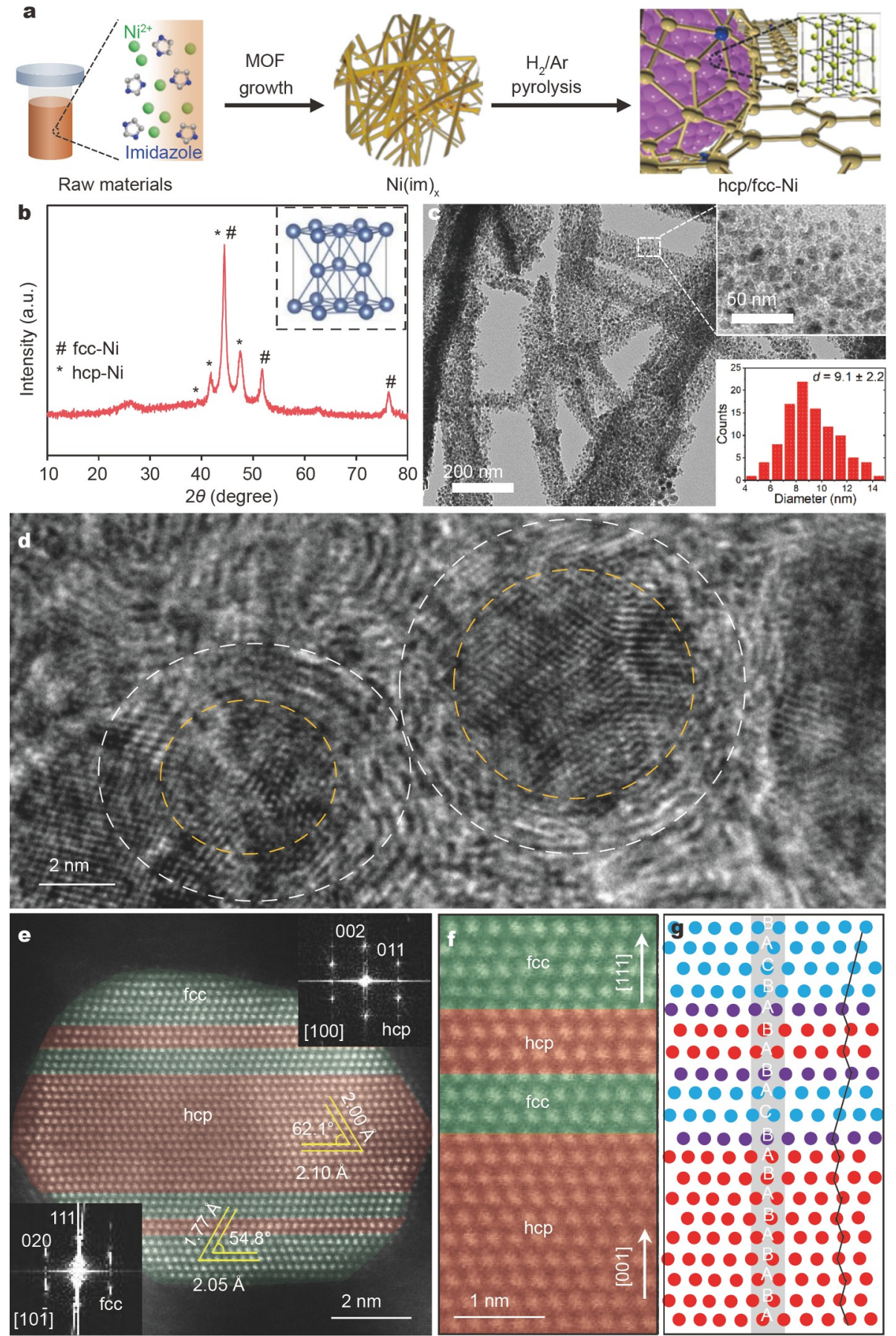

Figure 1 (a) Schematic illustrating the synthetic procedure of hcp/fcc-Ni. (b) XRD pattern (inset: hcp-Ni crystal structure model). (c) TEM image (insets: high-magnification TEM image and size distribution) and (d) HRTEM image (dotted yellow and white cycles indicating the outer profiles of Ni-NP and graphitic carbon layer, respectively) of hcp/fcc-Ni. (e) HAADF-STEM image of a typical Ni-NP in hcp/fcc-Ni. (f) Magnified HAADF-STEM image of Ni NPs with domains highlighted and (g) corresponding atomic scale schematics showing the stacking sequence of fcc (blue dots), hcp (red dots) phase and domain boundary (purple dots). 
in lengths and 100-300 $\mathrm{nm}$ in diameters (Fig. S1) was firstly synthesized by reacting imidazole (im) with $\mathrm{Ni}\left(\mathrm{CH}_{3} \mathrm{COO}\right)_{2}$. $4 \mathrm{H}_{2} \mathrm{O}$ under solvothermal conditions [39]. The obtained $\mathrm{Ni}(\mathrm{im})_{x}$ nanofiber precursor was then converted to hcp/fcc-Ni via a simple pyrolysis process under a $10 \mathrm{vol} \% \mathrm{H}_{2} / \mathrm{Ar}$ atmosphere. The X-ray diffraction (XRD) pattern (Fig. 1b) of hcp/fcc-Ni shows diffraction peaks at $41.5^{\circ}, 44.5^{\circ}$ and $47.5^{\circ}$, respectively, assignable to the (002), (001) and (101) planes of hcp-Ni crystal phase [28] (JCPDS: 45-1027), while the relatively weak diffraction peaks at $51.8^{\circ}$ and $76.4^{\circ}$ indicate the co-existence of fcc-Ni (JCPDS: $04-0850$ ). A broad peak centered at $\sim 26.3^{\circ}$ can be attributed to the presence of graphitic carbon (JCPDS: 41-1487) [40]. A typical scanning electron microscopy (SEM) image of hcp/fcc-Ni (Fig. S2) indicates that the shape of $\mathrm{Ni}(\mathrm{im})_{x}$ nanofiber precursor is retained by $\mathrm{hcp} / \mathrm{fcc}-\mathrm{Ni}$. The transmission electron microscopy (TEM) images (Fig. 1c) unveil that the Ni NPs in $\mathrm{hcp} / \mathrm{fcc}-\mathrm{Ni}$ with an average diameter of $9.1 \mathrm{~nm}$ are uniformly distributed in the carbon matrix. The high-resolution TEM (HRTEM) image (Fig. 1d) displays that the Ni NPs in hcp/fcc-Ni are covered by a thin carbon layer. The HAADF-STEM image of a typical NP in hcp/fcc-Ni (Fig. 1e) unveils an alternative hcp/fcc domain structure and the two neighboring hcp domains are separated by a fcc lamellae. The lattice spacings of 2.10 and $2.00 \AA$ with an interplanar angle of $62.1^{\circ}$ are measured from the hcp-Ni domain. The corresponding fast Fourier transformation (FFT) image (top right inset of Fig. 1e) can be indexed to the pattern with a [100] zone axis. The lattice spacings of 2.05 and $1.77 \AA$ with an interplanar angle of $54.8^{\circ}$ were measured from the fcc-Ni domain and the corresponding FFT image (bottom left inset of Fig. 1e) is assignable to the pattern with [10-1] zone axis. The magnified HAADF-STEM image of a Ni NP in hcp/ fcc-Ni (Fig. 1f) and the corresponding fcc/hcp stacking sequence (Fig. 1g) confirm a distinctive atomic lamellae stacking with clear domain boundaries (purple). The high resolution Ni 2p Xray photoelectron spectroscopic (XPS) spectrum (Fig. S3a) unveils the presence of $\mathrm{Ni}^{0}$ and $\mathrm{Ni}^{2+}$ in hcp/fcc-Ni $[41,42]$, while the high-resolution $\mathrm{C} 1 \mathrm{~s}$ spectrum (Fig. S4a) discloses the presence of C-N bonds [43]. The Raman spectrum (Fig. S5) displays two peaks centered at 1360 and $1589 \mathrm{~cm}^{-1}$, assignable respectively to the $\mathrm{D}$ and $\mathrm{G}$ bands of graphitic carbons $\left(I_{\mathrm{D}} / I_{\mathrm{G}}=\right.$ 1.02) $[44,45]$. The BET surface area of $h c p / f c c-N i$ is measured to be $104.6 \mathrm{~m}^{2} \mathrm{~g}^{-1}$ and the corresponding pore size distribution confirms the existence of microporous and mesoporous structures (Fig. S6a, b) [46]. The Ni content in hcp/fcc-Ni NPs is determined by the ICP analysis to be 48.38 wt.\%.

\section{Hydrogenation performance}

The $\mathrm{CH}$ performance of hcp/fcc-Ni was firstly evaluated using hydrogenation of nitrobenzene (NB) to aniline (AN) as a model reaction. Unless otherwise stated, all catalytic experiments were conducted in a mechanically stirred thermal reactor loaded with $10 \mathrm{~mL}$ solvent containing $20 \mathrm{mg}$ catalyst and $0.5 \mathrm{mmol}$ substrate. It has been widely reported that the hydrogenation of NB to AN involves multiple steps and intermediates as illustrated in
Scheme 1 [45].

The effect of reaction conditions on the catalytic performance and reaction process was elaborately investigated. First, it can be found that the sample calcined at $400^{\circ} \mathrm{C}$ give the optimum hydrogenation performance (Fig. S7). The effect of reaction temperature was examined under $1 \mathrm{MPa} \mathrm{H}_{2}$ pressure within a 2-h reaction period (Fig. $2 \mathrm{a}$ ). An increase in the reaction temperature from 20 to $30^{\circ} \mathrm{C}$ leads to the increased $\mathrm{NB}$ conversion from $65.6 \%$ to $100 \%$. When the reaction temperature is increased from 20 to $40^{\circ} \mathrm{C}$, the AN selectivity is increased from $72.3 \%$ to $100 \%$, accompanying a decreased nitrosobenzene (NSB) selectivity from $27.7 \%$ to $0 \%$. This suggests that higher temperature favors the hydrogenation of NSB. Notably, the other intermediate, phenylhydroxylamine (PAN), is undetectable under the experimental temperatures, which is likely due to the strong adsorption of PAN on the catalyst surface [47]. It is well known that when NSB and PAN co-exist, the condensation reaction occurs spontaneously to form azoxybenzene without the presence of any catalyst (Fig. S8). However, the formation of azoxybenzene is undetectable in our experiments (Fig. 2a and Fig. S9), confirming that the condensation of PAN and NSB intermediates is inhibited during the hydrogenation of $\mathrm{NB}$ due to the strong adsorption of PAN on the catalyst surface [47]. Fig. $2 \mathrm{~b}$ shows the effect of $\mathrm{H}_{2}$ pressure under $40^{\circ} \mathrm{C}$ within a 2-h reaction period. It unveils that an increase in $\mathrm{H}_{2}$ pressure leads to an increase in NB conversion, and $100 \% \mathrm{NB}$ conversion can be reached under $1 \mathrm{MPa} \mathrm{H}_{2}$. Compared with the effect on $\mathrm{NB}$ conversion, the effect of $\mathrm{H}_{2}$ pressure on AN selectivity is less dramatic. The AN selectivity of $80.4 \%$ can be achieved under a low $\mathrm{H}_{2}$ pressure of $0.1 \mathrm{MPa}$ and increases gradually to $100 \%$ at $0.8 \mathrm{MPa}$, which accompanies a decreased NSB selectivity from $19.6 \%$ to $0 \%$. These results suggest that higher $\mathrm{H}_{2}$ pressures are favorable for hydrogenation of NSB to AN. The effect of reaction time was then evaluated under $40^{\circ} \mathrm{C}$ and $1 \mathrm{MPa} \mathrm{H}_{2}$ (Fig. 2c). The $\mathrm{NB}$ conversion increases from $35.2 \%$ to $100 \%$ when the reaction time is increased from 10 to $120 \mathrm{~min}$, accompanying an increase in AN selectivity from $76.6 \%$ to $100 \%$ and an decrease in NSB selectivity from $23.4 \%$ to $0 \%$. Additionally, the $\mathrm{CH}$ performance of hcp/fcc-Ni in different solvents was studied (Fig. 2d). Under the experimental conditions, both NB conversion efficiency and AN selectivity follow the same trend of $\mathrm{H}_{2} \mathrm{O}(100 \% / 100 \%)>$ methanol $(95.8 \% / 100 \%)>$ ethanol $(67.2 \% / 91.7 \%)>2$-propanol $(35.2 \% / 89.8 \%)>1$-butanol $(30.8 \% / 87.5 \%)$, implying that the solvent with high polarity favors the $\mathrm{CH}$ of NB to AN. Such a correlation between the solvent polarity and NB conversion efficiency was also observed by others [48]. Such a polaritydependent performance order would also be due to the improved hydrophilicity of the $\mathrm{N}$-doped carbon support $[49,50]$. The stability of hcp/fcc-Ni was also examined (Fig. S10). The perfectly retained $\mathrm{NB}$ conversion and $\mathrm{AN}$ selectivity over six consecutive catalytic cycles confirm an excellent stability of hcp/ fcc-Ni. The excellent catalytic stability of hcp/fcc-Ni can be attributed to its excellent structural stability as evidenced by the perfectly retained morphological, structural and crystal phases

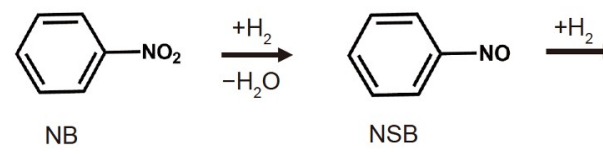

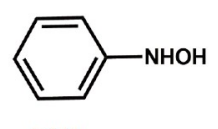

PAN

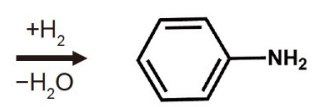

AN

Scheme 1 The reaction path of NB hydrogenation to AN. 

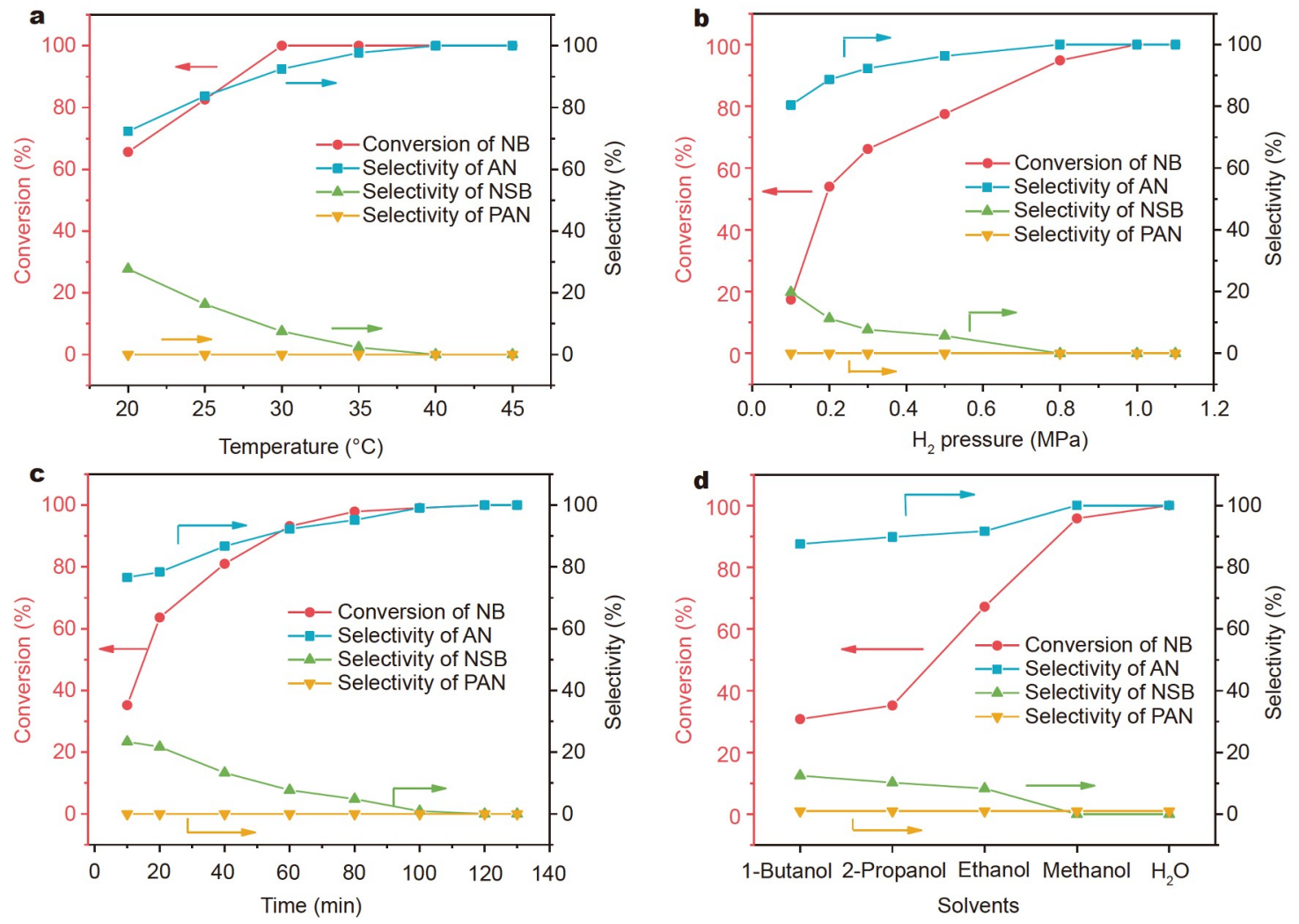

Figure 2 Effects of (a) reaction temperature ( $\left.2 \mathrm{~h}, 1 \mathrm{MPa} \mathrm{H}_{2}, \mathrm{H}_{2} \mathrm{O}\right)$, (b) $\mathrm{H}_{2}$ pressure $\left(40^{\circ} \mathrm{C}, 2 \mathrm{~h}, \mathrm{H}_{2} \mathrm{O}\right)$, (c) reaction time $\left(40^{\circ} \mathrm{C}, 1 \mathrm{MPa} \mathrm{H}_{2}, \mathrm{H}_{2} \mathrm{O}\right)$ and $(\mathrm{d})$ solvent $\left(40^{\circ} \mathrm{C}, 1 \mathrm{MPa} \mathrm{H}_{2}, 2 \mathrm{~h}\right)$ on NB conversion and AN selectivity for hcp/fcc-Ni-catalyzed hydrogenation of NB.

(Figs $\mathrm{S} 11$ and $\mathrm{S} 12$ ). The above results demonstrate the superiority of hcp/fcc-Ni toward hydrogenation of NB to AN in $\mathrm{H}_{2} \mathrm{O}$. In fact, among the reported catalysts to date, hcp/fcc-Ni is the best performed nonprecious catalyst for hydrogenation of NB to AN in $\mathrm{H}_{2} \mathrm{O}$ (Table S1).

It has been widely reported that the catalytic performance of TM catalysts can be strongly affected by their crystal phases [2123]. For comparative purpose, the pure fcc-phased Ni NPs (denoted as fcc-Ni) was synthesized by the same synthetic procedure as that used to synthesize hcp/fcc-Ni, except the $\mathrm{H}_{2} / \mathrm{Ar}$ mixed gas was replaced by pure $\mathrm{Ar}$ gas during pyrolysis (Fig. S13). The obtained fcc-Ni consists of pure fcc-Ni NPs (Fig. S14a) with similar morphology, porous structure and $\mathrm{Ni}$ NP sizes (Figs S3b, S4b, S5, S6c, d and S14b-h) as that of hcp/ fcc-Ni. The Ni content in fcc-Ni determined by ICP is 40.96 wt.\%, slightly lower than the $\mathrm{Ni}$ content in hcp/fcc-Ni (48.38 wt.\%). The $\mathrm{CH}$ performance of the resultant fcc- $\mathrm{Ni}$ toward NB was investigated. Fig. S15 shows the effect of reaction temperature on $\mathrm{NB}$ conversion and $\mathrm{AN}$ selectivity over a 2-h reaction period under $1 \mathrm{MPa}_{2}$ in $\mathrm{H}_{2} \mathrm{O}$. In strong contrast to hcp/fcc-Ni, under $40^{\circ} \mathrm{C}$, fcc-Ni can only achieve a $25.4 \% \mathrm{NB}$ conversion with an AN selectivity of $74.7 \%$. A high reaction temperature of $70^{\circ} \mathrm{C}$ is required for fcc-Ni to achieve a complete $\mathrm{NB}$ conversion with $100 \%$ AN selectivity, which is $30^{\circ} \mathrm{C}$ higher than that of hcp/fcc-Ni, confirming a poor $\mathrm{CH}$ activity of fcc-Ni NPs toward hydrogenation of NB.

To gain further insights, the kinetic studies were carried out. Fig. S16 shows the plots of NB conversion against reaction time under different reaction temperatures for hcp/fcc-Ni and fcc-Ni, respectively. The $-\ln \left(C_{t} / C_{0}\right)$ values derived from Fig. S16 are plotted against the reaction time under different reaction temperatures (Fig. 3a, c). The obtained linear relationships from all investigated reaction temperatures imply that the hydrogenation of NB catalyzed by both hcp/fcc-Ni and fcc-Ni follow the firstorder kinetics. The reaction rate constants $(k)$ are derived from the slopes of $-\ln \left(C_{t} / C_{0}\right)$ versus time plots. At $50^{\circ} \mathrm{C}, \mathrm{hcp} / \mathrm{fcc}-\mathrm{Ni}$ displays a $k_{50}$ of $9.96 \times 10^{-3} \mathrm{~min}^{-1}$, which is nearly seven times that for fcc-Ni $\left(k_{50}=1.49 \times 10^{-3} \mathrm{~min}^{-1}\right)$. Furthermore, the apparent activation energies $\left(E_{\mathrm{a}}\right)$ of 37.5 and $57.1 \mathrm{~kJ} \mathrm{~mol}^{-1}$ for $\mathrm{hcp} / \mathrm{fcc}-\mathrm{Ni}$ and fcc-Ni are derived from the corresponding Arrhenius plots (Fig. 3b, d), further confirming the superior kinetics of hcp/fcc-Ni over fcc-Ni. Considering both catalysts possess similar morphology, porous structure, Ni-NP sizes and $\mathrm{Ni}$ contents, it is very reasonable to attribute the superior hydrogenation performance of hcp/fcc-Ni to the presence of hcp-phased Ni [51,52].

\section{Computational studies}

DFT calculations were performed to depict the mechanistic insight of $\mathrm{CH}$ of $\mathrm{NB}$ on fcc- and hcp-Ni. Based on the structural characterization results, the (111) plane of fcc-Ni and the (011) plane of hcp-Ni were chosen for the DFT calculations. Fig. 4a shows the DFT-optimized stable NB parallel and vertical adsorption configurations on (011) plane of hcp-Ni and (111) plane of fcc-Ni, respectively. The calculated parallel and vertical $\mathrm{NB}$ adsorption energies are -1.93 and $-1.32 \mathrm{eV}$ for hcp-Ni and -1.54 and $-0.90 \mathrm{eV}$ for $\mathrm{fcc}-\mathrm{Ni}$, respectively. Compared with the vertical NB adsorptions, the parallel NB adsorptions on both catalyst surfaces are obviously stronger. The parallel adsorptions of $\mathrm{NB}$ on the hcp (011) and fcc (111) surfaces elongate the $\mathrm{N}-\mathrm{O}$ 

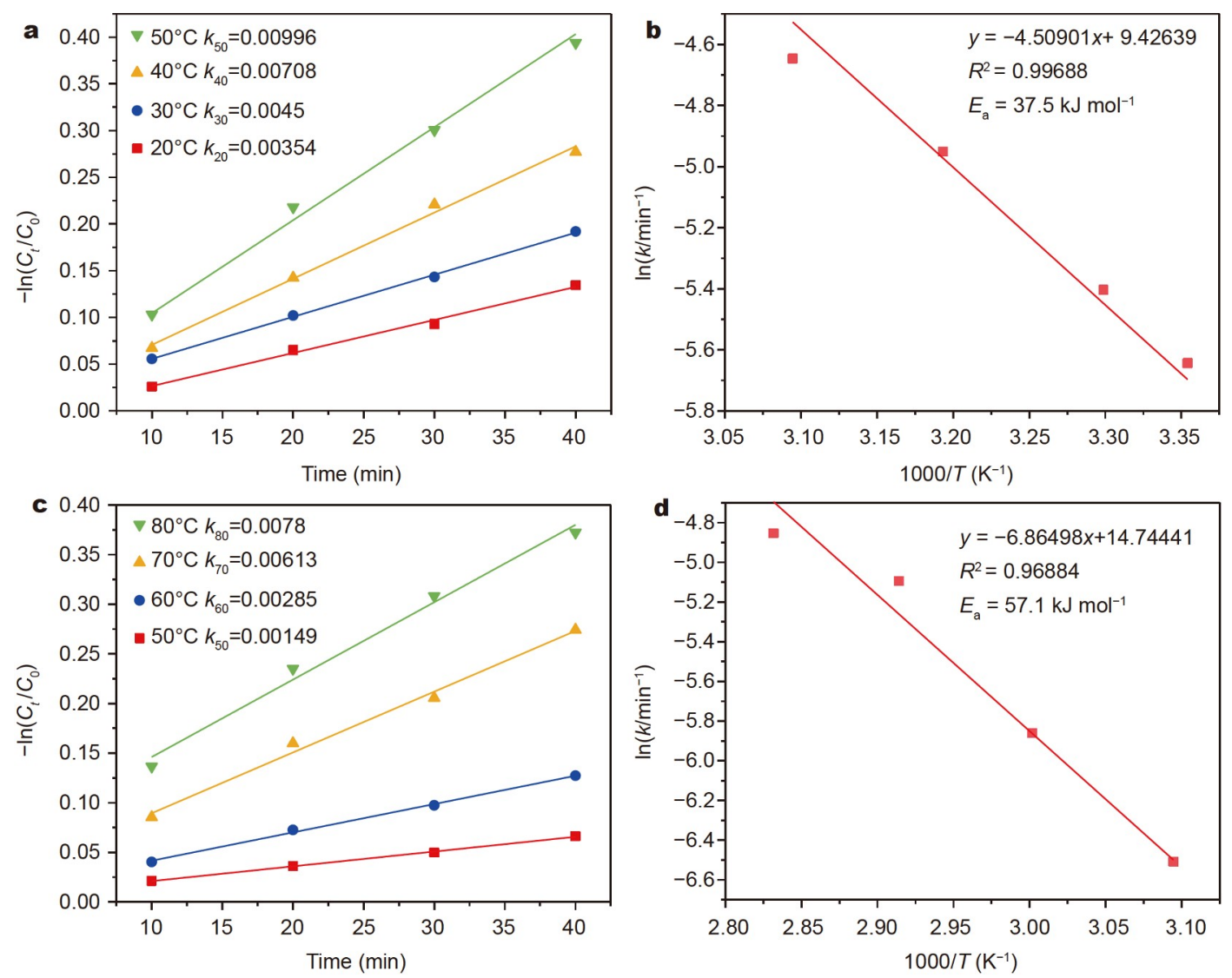

Figure 3 First-order kinetic fittings and corresponding Arrhenius plots for (a, b) hcp/fcc-Ni and (c, d) fcc-Ni-catalyzed hydrogenation of NB under different reaction temperatures. Reaction conditions: $0.2 \mathrm{MPa}_{2}, \mathrm{H}_{2} \mathrm{O}$.

bonds in the nitro group from 1.250 to 1.332 and $1.256 \AA$, respectively, indicating a stronger interaction between $\mathrm{NB}$ and hcp (011), favorable for the subsequent hydrogenation of the nitro group $[1,53,54]$. It has been widely reported that $\mathrm{CH}$ of nitro group in $\mathrm{NB}$ to form $\mathrm{AN}$ involves multiple sequential hydrogenation steps and each involves an transition state (TS)/ intermediate $[55,56]: \mathrm{PhNO}_{2} * \rightarrow \mathrm{PhNOOH}^{*}($ via TS1) $\rightarrow \mathrm{PhN}$ $(\mathrm{OH})_{2} *($ via TS2 $) \rightarrow \mathrm{PhNOH}^{*}($ via TS3 $) \rightarrow \mathrm{PhNHOH}^{*}($ via TS4) $\rightarrow \mathrm{PhNH}^{*}$ (via TS5) $\rightarrow \mathrm{PhNH}_{2}{ }^{*}$ (via TS6). Therefore, in this work, we calculated the TS structures and relative energies corresponding to each hydrogenation step of hcp-Ni- and fcc$\mathrm{Ni}$-catalyzed hydrogenation of nitro group in NB via the parallel adsorption reaction pathway. The DFT-optimized TS structures on the (011) plane of hcp-Ni and (111) plane of fcc-Ni are shown in Fig. 4b and Fig. S17, respectively, while the relative energies are summarized in Fig. 4c. Firstly, $\mathrm{NB}$ and $\mathrm{H}_{2}$ (a in Fig. 4c) adsorb on both hcp-Ni (011) and fcc-Ni (111) to form $\mathrm{PhNO}_{2}{ }^{*}$ and $\mathrm{H}^{*}$ (b in Fig. $4 \mathrm{c}$ ). The $1^{\text {st }}$ hydrogenation is to form $\mathrm{PhNOOH}^{*}(\mathbf{b} \rightarrow \mathbf{c}$ via TS1) on hcp-Ni (011) and fcc-Ni (111), which requires to overcome an energy barrier of 0.34 and $0.40 \mathrm{eV}$, respectively. The $2^{\text {nd }}$ hydrogenation forms $\mathrm{PhN}(\mathrm{OH})_{2}$ * $(\mathbf{d} \rightarrow \mathbf{e}$ via TS2) and needs to overcome an energy barrier of 0.28 and $0.31 \mathrm{eV}$ on the hcp-Ni (011) and fcc-Ni (111), respectively. Our calculations unveil that due to the special confrontations of the two attached hydroxyl groups on $\mathrm{N}, \mathrm{PhN}(\mathrm{OH})_{2}$ * is a highly active intermediate. Therefore, hcp-Ni (011)/fcc-Ni (111)-catalyzed activations of $\mathrm{N}-\mathrm{O}$ of $\mathrm{PhN}(\mathrm{OH})_{2}$ * to yield $\mathrm{PhNOH}^{*}$ and $\mathrm{OH}^{*}(\mathbf{e} \rightarrow \mathbf{f}$ via TS3) are exothermic by -1.63 and $-2.81 \mathrm{eV}$, with a low energy barrier of 0.33 and $0.58 \mathrm{eV}$, respectively. The calculated energy barriers involving in the processes of TS1-3 suggest an unambiguous thermodynamical favor of hcp-Ni (011) over fcc-Ni (111). It is worth noting that the generated $\mathrm{OH}^{*}$ can be spontaneously reduced to $\mathrm{H}_{2} \mathrm{O}$ by fcc- $\mathrm{Ni}(111)$ and desorbed into the solution, while for hcp-Ni (011), a small energy input of $0.12 \mathrm{eV}$ is required. However, $\mathrm{PhNOH}^{*}$ (g in Fig. $4 \mathrm{c}$ ) remains on the catalyst surface and reacts with $\mathrm{H}^{*}$ to form $\mathrm{PhNHOH}^{*}(\mathbf{h} \rightarrow$ i via TS4) that needs to overcome an energy barrier of 0.59 and $0.82 \mathrm{eV}$ on hcp-Ni (011) and fcc-Ni (111), respectively. This is followed by the cleavage of the remaining $\mathrm{N}-\mathrm{O}$ to form $\mathrm{PhNH}^{*}$ and $\mathrm{OH}^{*}(\mathbf{i} \rightarrow \mathbf{j}$ via TS5), which involves an energy barrier of 0.64 and $1.15 \mathrm{eV}$ for hcp-Ni (011) and fcc-Ni (111), respectively. In fact, the energy barrier involved in this reaction step is the highest of the entire reaction process. As such, the significantly reduced energy barrier by hcp-Ni (011) reflects its superiority over fcc-Ni (111) for $\mathrm{CH}$ of $\mathrm{NB}$ to $\mathrm{AN}$. The desorption of $\mathrm{OH}^{*}$ to form $\mathrm{PhNH}^{*}$ (k in Fig. 4c) is a spontaneous process for both hcp-Ni (011) and fcc-Ni (111). The subsequent hydrogenation to form $\mathrm{PhNH}_{2}{ }^{*}(\mathbf{l} \rightarrow \mathbf{m}$ via TS6) needs to overcome an energy barrier of 0.55 and $0.62 \mathrm{eV}$ for hcp-Ni (011) and fcc-Ni (111), respectively.

\section{Catalytic hydrogenation of other substrates}

Encouraged by the above results, we further examined the catalytic hydrogenation performance of hcp/fcc-Ni for a wide spectrum of nitro-, aldehyde-, ketone-, alkene- and $\mathrm{N}$ heterocyclic-compounds. All experiments were carried out in $\mathrm{H}_{2} \mathrm{O}$ 


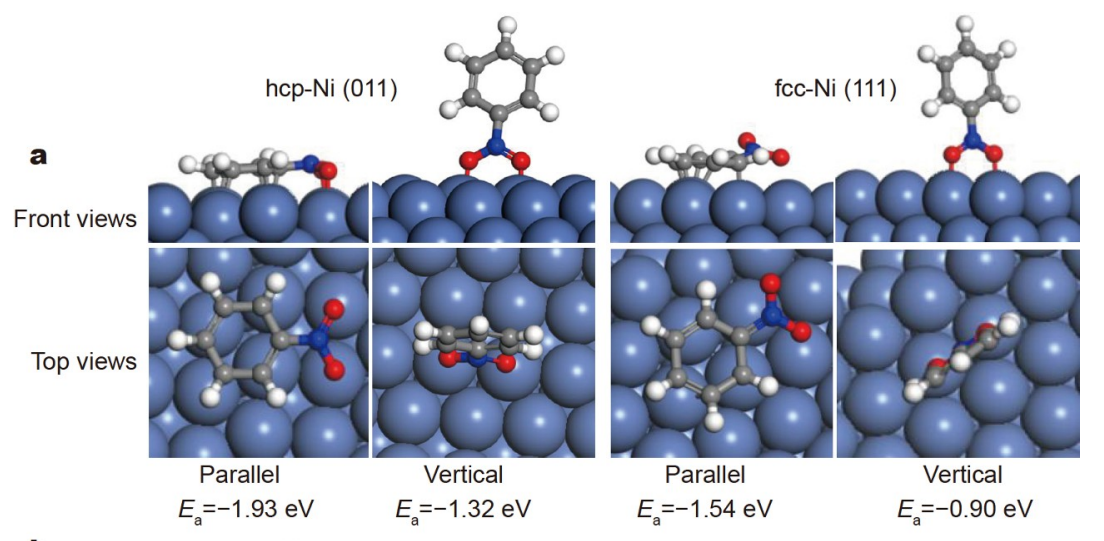

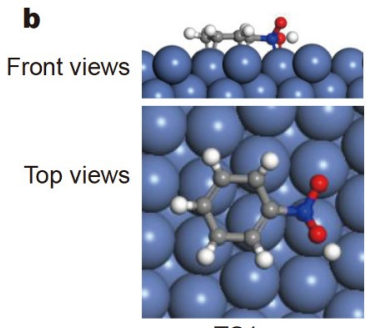

TS1

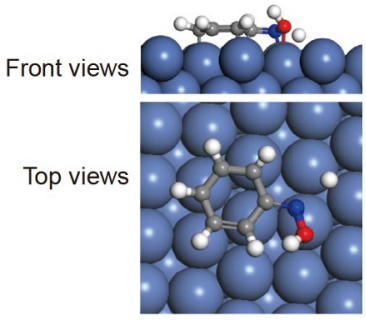

TS4

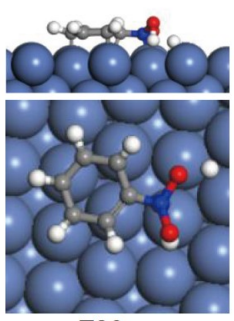

TS2

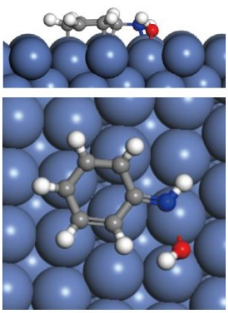

TS5

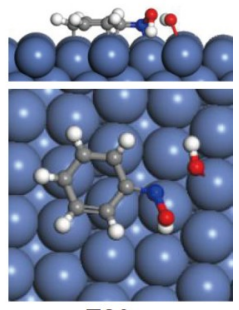

TS3

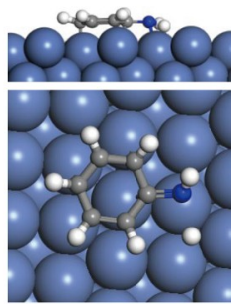

TS6

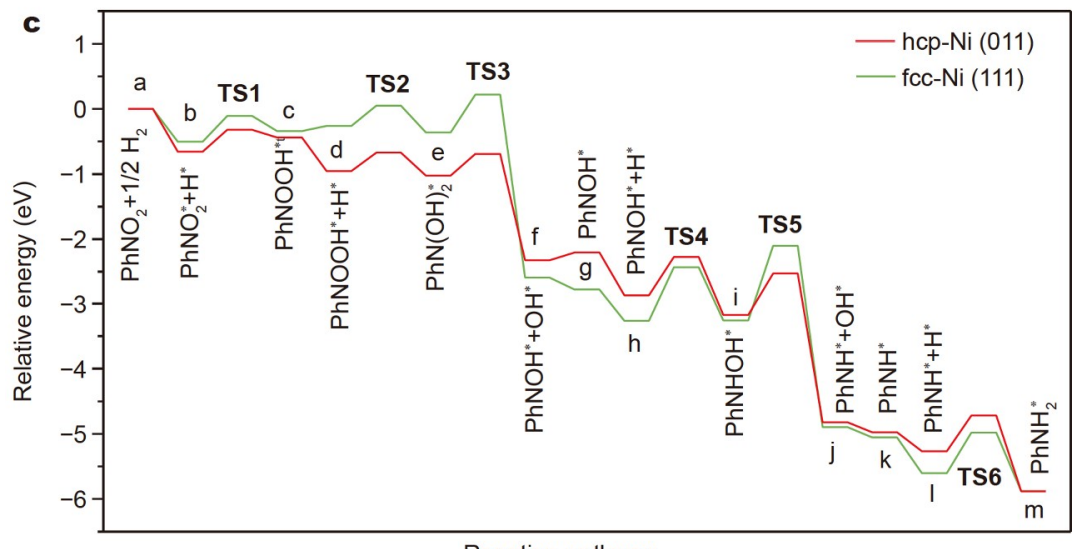

Reaction pathway

Figure 4 (a) Front and top views of the optimized parallel and vertical NB adsorption structures on hcp-Ni (011) and fcc-Ni (111) surfaces, respectively. (b) Front and top views of the optimized TS structures involving in the hcp-Ni (011)-catalyzed hydrogenation of NB to AN. (c) Energy profiles of the hcp-Ni $(011) /$ fcc-Ni (111)-catalyzed hydrogenation of $\mathrm{NB}$ to $\mathrm{AN}$. TS1: $\mathrm{PhNO}_{2}{ }^{*}+\mathrm{H}^{*} \rightarrow \mathrm{PhNOOH}^{*} ; \mathrm{TS} 2: \mathrm{PhNOOH} *+\mathrm{H}^{*} \rightarrow \mathrm{PhN}(\mathrm{OH})_{2} *$; TS3: $\mathrm{PhN}(\mathrm{OH})_{2} * \rightarrow$ $\mathrm{PhNOH}^{*}+\mathrm{OH}^{*}$; TS4: $\mathrm{PhNOH}^{*}+\mathrm{H}^{*} \rightarrow \mathrm{PhNHOH}^{*}$; TS5: $\mathrm{PhNHOH}^{*} \rightarrow \mathrm{PhNH}^{*}+\mathrm{OH}^{*} ;$ TS6: $\mathrm{PhNH}^{*}+\mathrm{H}^{*} \rightarrow \mathrm{PhNH}_{2}^{*}$. Dark blue, grey, blue, red and white represent $\mathrm{Ni}, \mathrm{C}, \mathrm{N}, \mathrm{O}$ and $\mathrm{H}$, respectively.

under $1 \mathrm{MPa} \mathrm{H}_{2}$ and different temperatures for a reaction period of $2 \mathrm{~h}$. As summarized Table 1 , hcp/fcc-Ni overperforms fcc-Ni for all cases investigated. For $\mathrm{CH}$ of nitro-containing compounds under $40^{\circ} \mathrm{C}$ (Entries 1 and 2, Table 1), hcp/fcc-Ni can readily achieve the quantitative substrate conversion and $100 \%$ selectivity toward the targeted products for $\mathrm{CH}$ of both $\mathrm{NB}$ and $m$-nitrotoluene (MNT) with a turnover frequency (TOF) of $217.0 \mathrm{~h}^{-1}$ for $\mathrm{CH}$ of $\mathrm{NB}$ and $237.9 \mathrm{~h}^{-1}$ for $\mathrm{CH}$ of MNT. In strong contrast, the substrate conversion, targeted product selectivity and TOF achieved by fcc-Ni are approximately half of that achieved by $\mathrm{hcp} / \mathrm{fcc}-\mathrm{Ni}$, indicating an inferior hydrogenation catalytic activity of fcc-Ni toward nitro-compounds. In fact, compared with the reported TM-based catalysts (Tables S1 and $\mathrm{S} 2$ ), hcp/fcc-Ni is the best performed catalyst for $\mathrm{CH}$ of nitrocompounds. Meanwhile, the excellent catalytic activity of hcp/ fcc-Ni also allows the hydrogenation to proceed at a significantly 
Table 1 Comparative performance of hcp/fcc-Ni and fcc-Ni for $\mathrm{CH}$ of various substrates ${ }^{\mathrm{a}}$

\begin{tabular}{|c|c|c|c|c|c|c|c|}
\hline Entry & Substrate & Product & Catalyst & $T\left({ }^{\circ} \mathrm{C}\right)$ & Conv. ${ }^{\mathrm{b}}(\%)$ & Sel. $^{\mathrm{b}}(\%)$ & $\mathrm{TOF}^{\mathrm{b}, \mathrm{c}}\left(\mathrm{h}^{-1}\right)$ \\
\hline \multirow{2}{*}{1} & & & hcp/fcc-Ni & 40 & 100 & 100 & 217.0 \\
\hline & & & fcc-Ni & 40 & 50.8 & 58.4 & 111.8 \\
\hline \multirow{2}{*}{2} & & & $\mathrm{hcp} / \mathrm{fcc}-\mathrm{Ni}$ & 30 & 100 & 100 & 237.9 \\
\hline & & & fcc-Ni & 30 & 62.7 & 46.7 & 123.3 \\
\hline \multirow{2}{*}{3} & & & hcp/fcc-Ni & 50 & 99.3 & 100 & 69.2 \\
\hline & & & fcc-Ni & 50 & 1.2 & 100 & 0.3 \\
\hline \multirow{2}{*}{4} & & & hcp/fcc-Ni & 60 & 100 & 98.8 & 179.5 \\
\hline & & & $\mathrm{fcc}-\mathrm{Ni}$ & 60 & 7.2 & 31.1 & 19.6 \\
\hline \multirow{2}{*}{5} & & & $\mathrm{hcp} / \mathrm{fcc}-\mathrm{Ni}$ & 80 & 91.3 & 94.2 & 54.2 \\
\hline & & & fcc-Ni & 80 & 0 & - & - \\
\hline \multirow{2}{*}{6} & & & $\mathrm{hcp} / \mathrm{fcc}-\mathrm{Ni}$ & 40 & 99.4 & 100 & 66.3 \\
\hline & & & fcc-Ni & 40 & 0.3 & 100 & 0.3 \\
\hline \multirow{2}{*}{7} & & & hcp/fcc-Ni & 40 & 100 & 100 & 349.4 \\
\hline & & & $\mathrm{fcc}-\mathrm{Ni}$ & 40 & 10.7 & 100 & 68.7 \\
\hline \multirow{2}{*}{8} & & & $\mathrm{hcp} / \mathrm{fcc}-\mathrm{Ni}$ & 90 & 100 & 100 & 35.1 \\
\hline & & & fcc-Ni & 90 & 6.5 & 100 & 0.6 \\
\hline
\end{tabular}

a) Reaction conditions: solvent: $\mathrm{H}_{2} \mathrm{O}$; reaction time: $2 \mathrm{~h} ; \mathrm{H}_{2}$ pressure: $1 \mathrm{MPa}$. b) Determined by GC-MS. c) Reaction time: 5 min.

reduced $\mathrm{H}_{2}$ pressure with a moderately increased reaction temperature (Fig. S18). In addition, the results (Fig. S19) show that well-known Raney Ni is superior to fcc-Ni but inferior to $\mathrm{hcp} / \mathrm{fcc}-\mathrm{Ni}$ in the hydrogenation of $\mathrm{NB}$, indicating its commercial potential.

The $\mathrm{CH}$ of aldehyde-compounds to corresponding alcohols such as furfural (FAL) to furfuryl alcohol (FOL) and cinnamaldehyde (CAL) to hydrocinnamyl alcohol (HCOL) is another class of important hydrogenation reactions to produce fine and bulk chemicals $[47,48,51]$. For $\mathrm{CH}$ of FAL to FOL under $50^{\circ} \mathrm{C}$ (Entry 3, Table 1), hcp/fcc-Ni can easily achieve 99.3\% FAL conversion and $100 \%$ FOL selectivity with a TOF of $69.2 \mathrm{~h}^{-1}$, outperforming the reported TM-based catalysts to date (Table S3). In a sharp contract, under the identical reaction conditions, fcc-Ni can only convert $1.2 \%$ FAL to FOL with a low TOF of $0.3 \mathrm{~h}^{-1}$ (Entry 3, Table 1). For CH of CAL to HCOL under $60^{\circ} \mathrm{C}$ (Entry 4, Table 1), hcp/fcc-Ni can achieve a quantitative CAL conversion and $98.8 \%$ HCOL selectivity with a TOF of $179.5 \mathrm{~h}^{-1}$, while fcc-Ni can only convert $7.2 \%$ CAL with a poor HCOL selectivity of $31.1 \%$ and a low TOF of $19.6 \mathrm{~h}^{-1}$. CH of other substrates including levulinic acid (LA) to $\gamma$-valerolactone (GVL), acetophenone (AOP) to 1-phenylethanol (PE), styrene (ST) to ethylbenzene (EBZ) and quinoline (QO) to tetrahydroquinoline (THQ) were also investigated to demonstrate the generic hydrogenation capability of hcp/fcc-Ni toward ketone-, alkene- and $\mathrm{N}$ heterocyclic-compounds. For $\mathrm{CH}$ of LA under $80^{\circ} \mathrm{C}$ (Entry 5, Table 1), hcp/fcc-Ni can realize $91.3 \%$ LA conversion and $94.2 \%$ GVL selectivity with a TOF of $54.2 \mathrm{~h}^{-1}$ that contrast strongly with the catalytic inactivity observed from fcc-Ni. As shown in Table 1 (Entries 6-8), hcp/fcc-Ni can quantitatively hydrogenate $\mathrm{CYC}$ to $\mathrm{CYH}$ under $40^{\circ} \mathrm{C}$ with a TOF of $66.3 \mathrm{~h}^{-1}$, ST to EBZ under $40^{\circ} \mathrm{C}$ with a TOF of $349.4 \mathrm{~h}^{-1}$, and QO to THQ under $90^{\circ} \mathrm{C}$ with a TOF of $35.1 \mathrm{~h}^{-1}$, while under the corresponding temperatures, $\mathrm{fcc}-\mathrm{Ni}$ is barely active and can only convert $0.3 \%-10.7 \%$ substrates to the targeted products. These results demonstrate the superb catalytic performance and unprecedented generic applicability of $\mathrm{hcp} / \mathrm{fcc}-\mathrm{Ni}$ for hydro- genation reactions, and exemplify the effectiveness of engineering Ni NPs with hcp phase to enhance their intrinsic catalytic activity.

\section{CONCLUSIONS}

In summary, we have demonstrated a facile pyrolysis approach to directly convert Ni-containing MOF precursor into hcpphased Ni NPs on carbon support. We theoretically and experimentally exemplified that introducing hcp crystal phase into Ni NPs can dramatically enhance the intrinsic catalytic activity toward a wide spectrum of hydrogenation reactions. We anticipated that the unveiled crystal phase engineering design approach would be adoptable to other types of reactions.

Received 31 August 2021; accepted 28 October 2021; published online 2 December 2021

1 Yang H, Bradley SJ, Chan A, et al. Catalytically active bimetallic nanoparticles supported on porous carbon capsules derived from metalorganic framework composites. J Am Chem Soc, 2016, 138: 1187211881

2 Macino M, Barnes AJ, Althahban SM, et al. Tuning of catalytic sites in $\mathrm{Pt} / \mathrm{TiO}_{2}$ catalysts for the chemoselective hydrogenation of 3-nitrostyrene. Nat Catal, 2019, 2: 873-881

3 Gong W, Lin Y, Chen $\mathrm{C}$, et al. Nitrogen-doped carbon nanotube confined Co- $\mathrm{N}_{x}$ sites for selective hydrogenation of biomass-derived compounds. Adv Mater, 2019, 31: 1808341

4 Zhang L, Zhou M, Wang A, et al. Selective hydrogenation over supported metal catalysts: from nanoparticles to single atoms. Chem Rev, 2020, 120: 683-733

5 Formenti D, Ferretti F, Scharnagl FK, et al. Reduction of nitro compounds using 3d-non-noble metal catalysts. Chem Rev, 2019, 119: 2611-2680

6 Tian $\mathrm{S}, \mathrm{Hu} \mathrm{M}, \mathrm{Xu} \mathrm{Q}$, et al. Single-atom $\mathrm{Fe}$ with $\mathrm{Fe}_{1} \mathrm{~N}_{3}$ structure showing superior performances for both hydrogenation and transfer hydrogenation of nitrobenzene. Sci China Mater, 2020, 64: 642-650

7 Wang Y, Xu A, Wang Z, et al. Enhanced nitrate-to-ammonia activity on copper-nickel alloys via tuning of intermediate adsorption. J Am Chem Soc, 2020, 142: 5702-5708

8 Tang F, Wang L, Dessie Walle M, et al. An alloy chemistry strategy to 
tailoring the d-band center of $\mathrm{Ni}$ by $\mathrm{Cu}$ for efficient and selective catalytic hydrogenation of furfural. J Catal, 2020, 383: 172-180

9 Wang $\mathrm{P}$, Shao Q, Cui X, et al. Hydroxide-membrane-coated $\mathrm{Pt}_{3} \mathrm{Ni}$ nanowires as highly efficient catalysts for selective hydrogenation reaction. Adv Funct Mater, 2018, 28: 1705918

10 Liu Y, Liu X, Feng Q, et al. Intermetallic $\mathrm{Ni}_{x} M_{y}(M=\mathrm{Ga}$ and $\mathrm{Sn})$ nanocrystals: a non-precious metal catalyst for semi-hydrogenation of alkynes. Adv Mater, 2016, 28: 4747-4754

11 Gong W, Yuan Q, Chen C, et al. Liberating N-CNTs confined highly dispersed Co- $\mathrm{N}_{x}$ sites for selective hydrogenation of quinolines. Adv Mater, 2019, 31: 1906051

12 Wang D, Al-Mamun M, Gong W, et al. Converting $\mathrm{Co}^{2+}$-impregnated g- $\mathrm{C}_{3} \mathrm{~N}_{4}$ into $\mathrm{N}$-doped CNTs-confined Co nanoparticles for efficient hydrogenation rearrangement reactions of furanic aldehydes. Nano Res, 2021, 14: 2846-2852

13 Mateen M, Shah K, Chen Z, et al. Selective hydrogenation of N-heterocyclic compounds over rhodium-copper bimetallic nanocrystals under ambient conditions. Nano Res, 2019, 12: 1631-1634

14 Xiao Q, Sarina S, Waclawik ER, et al. Alloying gold with copper makes for a highly selective visible-light photocatalyst for the reduction of nitroaromatics to anilines. ACS Catal, 2016, 6: 1744-1753

15 Petró J, Bóta A, László K, et al. A new alumina-supported, not pyrophoric Raney-type Ni-catalyst. Appl Catal A-Gen, 2000, 190: 73-86

16 Zhou $\mathrm{Y}$, gao $\mathrm{Y}$, zhong $\mathrm{x}$, et al. Electrocatalytic upgrading of ligninderived bio-oil based on surface-engineered $\mathrm{PtNiB}$ nanostructure. Adv Funct Mater, 2019, 29: 1807651

17 Ni J, Leng W, Mao J, et al. Tuning electron density of metal nickel by support defects in $\mathrm{Ni} / \mathrm{ZrO}_{2}$ for selective hydrogenation of fatty acids to alkanes and alcohols. Appl Catal B-Environ, 2019, 253: 170-178

18 Khan NA, Chen JG. Correlating mechanical strain with low-temperature hydrogenation activity on submonolayer $\mathrm{Ni} / \mathrm{W}(110)$ surfaces. J Phys Chem B, 2003, 107: 4334-4341

19 Crespo-Quesada M, Yarulin A, Jin M, et al. Structure sensitivity of alkynol hydrogenation on shape- and size-controlled palladium nanocrystals: which sites are most active and selective? J Am Chem Soc, 2011, 133: 12787-12794

20 Lv Y, Han M, Gong W, et al. Fe-Co alloyed nanoparticles catalyzing efficient hydrogenation of cinnamaldehyde to cinnamyl alcohol in water. Angew Chem Int Ed, 2020, 59: 23521-23526

21 Han M, Liu Q, He J, et al. Controllable synthesis and magnetic properties of cubic and hexagonal phase nickel nanocrystals. Adv Mater, 2007, 19: 1096-1100

22 Zhang C, Yang J, Liu Y, et al. Catalytic hydrogenation of nitrophenols by cubic and hexagonal phase unsupported Ni nanocrystals. ChemistrySelect, 2019, 4: 42-48

23 Wegner S, Rutz C, Schütte K, et al. Soft, wet-chemical synthesis of metastable superparamagnetic hexagonal close-packed nickel nanoparticles in different ionic liquids. Chem Eur J, 2017, 23: 6330-6340

24 Gao X, Zhu S, Dong M, et al. MOF-derived hcp-Co nanoparticles encapsulated in ultrathin graphene for carboxylic acids hydrogenation to alcohols. J Catal, 2021, 399: 201-211

25 Li N, Tan H, Ding X, et al. Phase-mediated robust interfacial electroncoupling over core-shell Co@carbon towards superior overall water splitting. Appl Catal B-Environ, 2020, 266: 118621-118628

26 Yun Q, Lu Q, Li C, et al. Synthesis of PdM $(\mathrm{M}=\mathrm{Zn}, \mathrm{Cd}, \mathrm{ZnCd})$ nanosheets with an unconventional face-centered tetragonal phase as highly efficient electrocatalysts for ethanol oxidation. ACS Nano, 2019, 13: $14329-14336$

27 Chen Y, Lai Z, Zhang X, et al. Phase engineering of nanomaterials. Nat Rev Chem, 2020, 4: 243-256

28 LaGrow AP, Cheong S, Watt J, et al. Can polymorphism be used to form branched metal nanostructures? Adv Mater, 2013, 25: 1552-1556

29 Zhang C, Guo X, Yuan Q, et al. Ethyne-reducing metal-organic frameworks to control fabrications of core/shell nanoparticles as catalysts. ACS Catal, 2018, 8: 7120-7130

30 Su J, Yang Y, Xia G, et al. Ruthenium-cobalt nanoalloys encapsulated in nitrogen-doped graphene as active electrocatalysts for producing hydrogen in alkaline media. Nat Commun, 2017, 8: 14969-14979

31 Cheng H, Yang N, Lu Q, et al. Syntheses and properties of metal nanomaterials with novel crystal phases. Adv Mater, 2018, 30: 1707189

32 Kresse G, Furthmüller J. Efficient iterative schemes for ab initio totalenergy calculations using a plane-wave basis set. Phys Rev B, 1996, 54: $11169-11186$

33 Kresse G, Furthmüller J. Efficiency of ab-initio total energy calculations for metals and semiconductors using a plane-wave basis set. Comput Mater Sci, 1996, 6: 15-50

34 Perdew JP, Burke K, Ernzerhof M. Generalized gradient approximation made simple. Phys Rev Lett, 1996, 77: 3865-3868

35 Ernzerhof M, Scuseria GE. Assessment of the Perdew-Burke-Ernzerhof exchange-correlation functional. J Chem Phys, 1999, 110: 5029-5036

36 Grimme S. Semiempirical GGA-type density functional constructed with a long-range dispersion correction. J Comput Chem, 2006, 27: 1787-1799

37 Henkelman G, Uberuaga BP, Jónsson H. A climbing image nudged elastic band method for finding saddle points and minimum energy paths. J Chem Phys, 2000, 113: 9901-9904

38 Henkelman G, Jónsson $\mathrm{H}$. Improved tangent estimate in the nudged elastic band method for finding minimum energy paths and saddle points. J Chem Phys, 2000, 113: 9978-9985

39 Wu JX, Yuan WW, Xu M, et al. Ultrathin 2D nickel zeolitic imidazolate framework nanosheets for electrocatalytic reduction of $\mathrm{CO}_{2}$. Chem Commun, 2019, 55: 11634-11637

40 Chen Z, Yang W, Wu Y, et al. Atomic iron on mesoporous N-doped carbon to achieve dehydrogenation reaction at room temperature. Nano Res, 2020, 13: 3075-3081

41 Zhang $\mathrm{H}$, Liu $\mathrm{Y}$, Chen $\mathrm{T}$, et al. Unveiling the activity origin of electrocatalytic oxygen evolution over isolated $\mathrm{Ni}$ atoms supported on a $\mathrm{N}$ doped carbon matrix. Adv Mater, 2019, 31: 1904548

42 Rui K, Zhao G, Chen Y, et al. Hybrid 2D dual-metal-organic frameworks for enhanced water oxidation catalysis. Adv Funct Mater, 2018, 28: 1801554

43 Wang $\mathrm{C}$, Yang $\mathrm{H}$, Zhang $\mathrm{Y}$, et al. NiFe alloy nanoparticles with hcp crystal structure stimulate superior oxygen evolution reaction electrocatalytic activity. Angew Chem Int Ed, 2019, 58: 6099-6103

44 Zhu Y, Sun W, Chen W, et al. Scale-up biomass pathway to cobalt single-site catalysts anchored on N-doped porous carbon nanobelt with ultrahigh surface area. Adv Funct Mater, 2018, 28: 1802167

45 Chen S, Feng Y, Wang J, et al. Free-standing N-doped hollow carbon fibers as high-performance anode for potassium ion batteries. Sci China Mater, 2020, 64: 547-556

$46 \mathrm{Lu} \mathrm{Q}, \mathrm{Yu}$ J, Zou X, et al. Self-catalyzed growth of Co, N-codoped CNTs on carbon-encased $\operatorname{CoS}_{x}$ surface: A noble-metal-free bifunctional oxygen electrocatalyst for flexible solid $\mathrm{Zn}$-air batteries. Adv Funct Mater, 2019, 29: 1904481

47 Corma A, Concepción P, Serna P. A different reaction pathway for the reduction of aromatic nitro compounds on gold catalysts. Angew Chem Int Ed, 2007, 46: 7266-7269

48 Song T, Ren P, Duan Y, et al. Cobalt nanocomposites on N-doped hierarchical porous carbon for highly selective formation of anilines and imines from nitroarenes. Green Chem, 2018, 20: 4629-4637

49 Yang W, Liu X, Yue X, et al. Bamboo-like carbon nanotube/ $/ \mathrm{Fe}_{3} \mathrm{C}$ nanoparticle hybrids and their highly efficient catalysis for oxygen reduction. J Am Chem Soc, 2015, 137: 1436-1439

50 He L, Weniger F, Neumann H, et al. Synthesis, characterization, and application of metal nanoparticles supported on nitrogen-doped carbon: catalysis beyond electrochemistry. Angew Chem Int Ed, 2016, 55: $12582-12594$

51 Zhou X, Zhao H, Liu S, et al. Engineering nano-ordered of Ni nanoparticles on KIT-6 for enhanced catalytic hydrogenation of nitrobenzene. Appl Surf Sci, 2020, 525: 146382-146390

52 Meng $\mathrm{X}$, Cheng $\mathrm{H}$, Akiyama $\mathrm{Y}$, et al. Selective hydrogenation of nitrobenzene to aniline in dense phase carbon dioxide over $\mathrm{Ni} / \gamma-\mathrm{Al}_{2} \mathrm{O}_{3}$ : Significance of molecular interactions. J Catal, 2009, 264: 1-10

53 Westerhaus FA, Jagadeesh RV, Wienhöfer G, et al. Heterogenized cobalt oxide catalysts for nitroarene reduction by pyrolysis of molecularly defined complexes. Nat Chem, 2013, 5: 537-543

54 Sun Q, Wang N, Zhang T, et al. Zeolite-encaged single-atom rhodium catalysts: Highly-efficient hydrogen generation and shape-selective 
tandem hydrogenation of nitroarenes. Angew Chem Int Ed, 2019, 58: 18570-18576

55 Sheng T, Qi YJ, Lin X, et al. Insights into the mechanism of nitrobenzene reduction to aniline over Pt catalyst and the significance of the adsorption of phenyl group on kinetics. Chem Eng J, 2016, 293: 337-344

56 Cheong WC, Yang W, Zhang J, et al. Isolated iron single-atomic sitecatalyzed chemoselective transfer hydrogenation of nitroarenes to arylamines. ACS Appl Mater Interfaces, 2019, 11: 33819-33824

Acknowledgements This work was financially supported by the National Natural Science Foundation of China (51902311 and 51871209).

Author contributions Lv Y carried out the materials fabrication, characterizations and performance measurements, and wrote the initial manuscript; Mao X and Du A performed and guided theoretical analysis; Wang D, Chen C and Lin Y did some characterizations; Liu P, Wang G and Zhang H performed some data analysis; Gong $\mathrm{W}$ and Zhao $\mathrm{H}$ conceived and supervised this study, and revised the manuscript. All authors contributed to the general discussion.

Conflict of interest The authors declare that they have no conflict of interest.

Supplementary information Experimental details and supporting data are available in the online version of the paper.

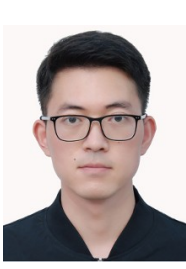

Yang Lv received his MSc degree from the University of Science and Technology of China. He is working on the synthesis of novel nanomaterials for catalytic reactions.

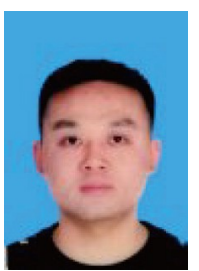

Xin Mao is now a PhD student under Prof. Aijun Du's supervision at the School of Chemistry and Physics, Queensland University of Technology. His research interest mainly focuses on computational design of some nonprecious metal-based materials for energy conversion and storage processes, such as hydrogen evolution reactions, oxygen evolution/reduction reactions, and $\mathrm{CO}_{2}$ reduction reactions.

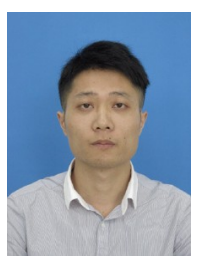

Wanbing Gong received his $\mathrm{PhD}$ degree from the University of Science and Technology of China in 2018. Then, he joined Hefei Institutes of Physical Science, Chinese Academy of Sciences as a postdoctor. He took a Research Associate Professor position at the University of Science and Technology of China in 2021. His current research interests focus on searching for new nonprecious catalytic materials and novel catalytic systems to meet the need of industries.

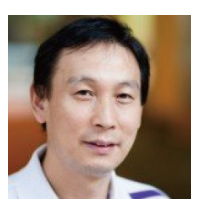

Aijun Du obtained his $\mathrm{PhD}$ in nuclear and particle physics (2002) from Fudan University, China. He worked at Australian Institute for Bioengineering and Nanotechnology, University of Queensland for nine years. He joined Queensland University of Technology in 2013 as an Associate Professor and was promoted to a full Professor in 2017. His research focuses on the development of innovative nanomaterials for clean energy, environmental and nanoelectronics applications.

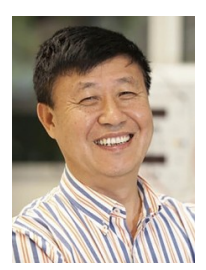

Huijun Zhao obtained his $\mathrm{PhD}$ in chemistry (1994) from the University of Wollongong, Australia, and subsequently held Research Fellow/Senior Research Fellow positions at the University of Wollongong and University of Western Sydney. He took a Lecturer position at Griffith University and was promoted to Chair Professor of chemistry (2005). One of his current pursuits is to explore new means to unlock the catalytic powers of nonprecious materials for important reactions.

\section{hcp 晶相的 $\mathrm{Ni}$ 纳米颗粒对不同官能团的通用催化加氢 活性}

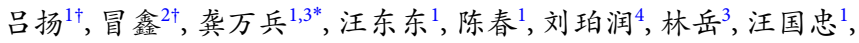
张海民1, 杜爱军 ${ }^{2 *}$, 赵惠军 ${ }^{1,4^{*}}$

摘要 催化加氢是生产高附加值燃料和精细化学品的重要工业途径, 但需要高效的催化剂, 尤其是廉价的非贵金属催化剂. 迄今为止, 大多 数高性能催化加氢催化剂都是由贵金属材料制成, 并且这些催化剂都 只能用于催化一种或几种特定的反应. 在这里, 我们例证了一种晶相工 程方法, 其能赋予 $\mathrm{Ni}$ 纳米颗粒 $(\mathrm{NPs})$ 卓越的、广谱的内在催化加氢活性. 这种负载于碳载体上含有 $h c p$ 晶相的 Ni NPs催化剂通过直接碳化热解 $\mathrm{Ni}$ 味唑MOF前驱体获得. 在纯水中, 含 $\mathrm{hcp}$ 相的 $\mathrm{Ni}$ NPs对硝基、醛、 酮、烯烃和 $\mathrm{N}$ 杂环化合物表现出前所未有的加氢催化活性, 优于类似 物 fcc- $\mathrm{Ni}$ 和目前报道的其他过渡金属催化剂. 密度泛函理论计算表明, hcp-Ni通过增强底物吸附强度和降低速率决定步骤的反应势垒能共同 来提高内在催化氢化活性. 我们预计这项工作中揭示的晶相工程设计 方法将适用于其他类型的反应. 